NASA Technical Memorandum 101373

AIAA-89-0069

\title{
Convective Flows in Enclosures With Vertical Temperature or Concentration Gradients
}

L.W. Wang and A.T. Chai

Lewis Research Center

Cleveland, Ohio

and

D.J. Sun

National Cheng Kung University

Taiwan, R.O.C.

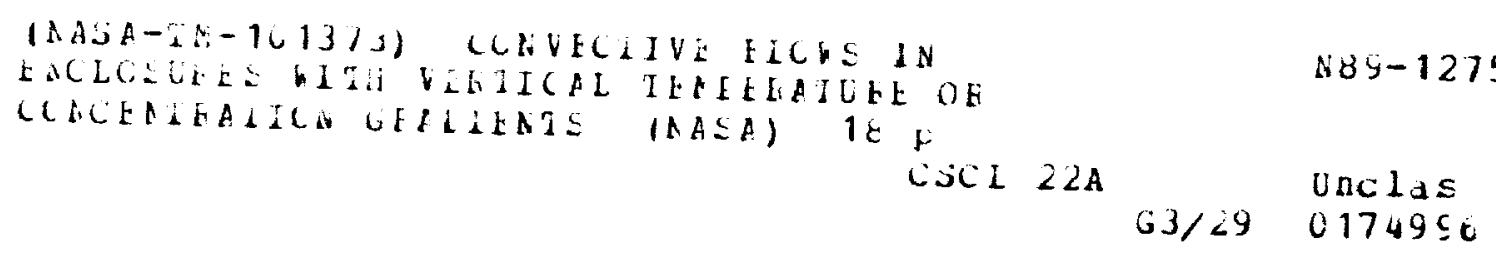

Prepared for the

27th Aerospace Sciences Meeting

sponsored by the American Institute of Aeronautics and Astronautics

Reno, Nevada, January 9-12, 1989

\section{NMSA}




\title{
CONVECTIVE FLOWS IN ENCLOSURES WITH VERTICAL TEMPERATURE OR CONCENTRATION GRADIENTS
}

\author{
L.W. Wang* and A.T. Chai \\ National Aeronautics and Space Administration \\ Lewis Research Center \\ Cleveland, Ohio U.S.A.
}

and

D.J. Sun

National Cheng Kung University

Taiwan, R.O.C.

\section{Abstract}

The transport process in the fluid phase during the growth of a crystal has a profound influence on the structure and quality of the solld phase. In vertical growth techniques the fluid phase is often subjected to vertical temperature and concentration gradients. The main objectlve of the present work is to obtain more experimental data on convective flows in enclosures with vertical temperature or concentration gradients.

Among actual crystal systems the parameters vary widely. The parametric ranges studied herein for mass transfer experiments are mainly dictated by the electrochemical system employed herein to impose concentration gradients. Temperature or concentration differences are maintalned between two horizontal end walls. The other walls are kept insulated.

Experimental measurements and observations were made of the heat transfer or mass transfer. flow patterns, and the mean and fluctuating temperature distribution. For purely thermal cases. the experiment covers the ranges of thermal Rayleigh number $\mathrm{Ra}=9 \times 10^{6}$ to $2 \times 10^{9}$, aspect ratio $\mathrm{Ar}=0.65$ to 2.6. Prandt 1 number $\mathrm{Pr}=4.0$ to 7.0 . The method used to visualize the flow pattern in the thermal cases is an electrochemical ph-indicator method. For purely solutal cases the experiment covers the ranges of solutal Rayleigh number $\mathrm{Ra}_{\mathrm{m}}=1.0 \times 10^{9}$ to $2.4 \times 10^{11}, \mathrm{Ar}=0.68$ to 1.34 , $S C=2000$ to 2100 . Laser shadowgraphs is employed to visualize flow patterns in the solutal cases.

The results of the present experiments for the purely thermal cases are adequately correlated by the equation $\mathrm{Nu}=0.0862 \mathrm{Ra} 0.322$ in the range $9 \times 10^{6}$ \&a $<2 \times 10^{9}$. For the purely solutal cases. the mass transfer data can be correlated by the equation $S h=0.1326(\mathrm{SC} \mathrm{Gr}) 0.328$ in the range $1 \times 10^{9}<\operatorname{Ram}_{\mathrm{m}}<2.4 \times 10^{11}$.

\section{Nomenclature}

Ar aspect ratio $(=d / L)$
$C_{b} \quad$ bulk concentration of $\mathrm{CuSO}_{4}$
$C_{1} \quad$ constant of heat transport correlation
$C_{2} \quad$ constant of mass transport correlation
$d \quad$ height of enclosure

* National Research Council - NASA Research Associate.
D

Gr

$\mathrm{Gr}$

g

h

I

$i_{L}$

N

Nu

n

$\mathrm{Ra}$

$\mathrm{Ra}_{\mathrm{m}}$

Sc

Sh

$T$

Th

TC

$\mathrm{t}$

V

$W$

$x, y, z$

coordinates

$\bar{x}, \bar{y}, \bar{z}$ dimensionless coordinates

$z^{*} \quad$ charge number of copper

$\bar{\beta}$

$\beta$ volumetric coefficient of solutal expansion

volumetric coefficient of thermal expansion

$\delta_{s}$

solutal diffusivity

Faraday's constant

thermal Grashof number

solutal Grashof number

gravitational acceleration

average mass transfer coefficient

current

length of enclosurel

buoyancy ratio

Nusselt number

exponential constant in transport correlation

thermal Rayleigh number ( $=\mathrm{Gr}$ Pr)

solutal Rayleigh number $\left(=G r_{m} S C\right)$

Schmidt number

Sherwood number

temperature

not wall temperature

cold wall temperature

time

voltage

thickness of solutal boundary layer 


\section{Introduction}

The growth of crystals is a coupled process of heat and mass transfer, fluid flow, phase transformations, and chemical reactions. Although the technology of crystal growth is well grounded in physical chemistry, the treatment of the transport phenomena has been relatively rudimentary and empirical. Recently, it was recognized that convection, as a result of temperature or concentration gradients, 1 occurs in many aspects of materials processing including solldification, oxidation of surface material, and crystal growth.

The rate of crystal growth is often limited by the mass transfer because it is the slowest process. In almost all the commonly used techniques the parent phase is a fluid. As in most nonequilibrium processes involving a fluld, convection plays a dominant role in that it affects the fluidphase composition and temperature at the phase interface. The fluid motion in many cases is determined by the locally generated motion. The flows are due either to the effects of temperature and/or concentration gradients in a body-force field. 2 In some crystal-growth techniques, the completely confined fluid phase is subject to vertical temperature and/or concentration gradients. To gain insights on such flows, an experimental program was initiated to study flows in rectangular enclosures with vertical temperature or concentration gradients between horizontal end walls.

The present work for purely thermal cases is intended to give a comprehensive understanding of natural convection heat transfer in enclosures with thermaliy insulated vertical walls by systematicaliy varying the parameters $\mathrm{Ra}$ and $\mathrm{Ar}$. The fluid is tap water in these thermal experiments.

An electrochemical system based on a diffusioncontrolled electrode reaction was employed to create the vertical concentration gradients. The apparatus was a rectangular cavity with the horizontal end walls being the electrodes. All other walls were insulated. The fluld was a copper sulphate $\left(\mathrm{CuSO}_{4}\right)$-acid $\left(\mathrm{H}_{2} \mathrm{SO}_{4}\right)$ solution for purely solutal experiments.

\section{Experimental Design}

\section{Dimensionless Parameters}

Based on the basic differential equation for natural convection in an enclosure with thermal or solutal buoyancy forces (Fig. 1), it can be shown that the following dimensionless parameters are important in the present work.

Thermal Grashof number, $G r=g \beta \Delta T d^{3} / \nu^{2}$ Prandt l number, $\operatorname{Pr}=v / \alpha$

Schmidt number, $S C=v / 0$

Solutal Grashof number, $\mathrm{Gr}_{\mathrm{m}}=\mathrm{g} \bar{\beta} \Delta \mathrm{Cd}^{3} / \mathrm{v}^{2}$

Aspect ratio, $A=d / L$

With the present system the ranges of the dimensionless parameters covered for purely thermal cases are $\operatorname{Pr}=4.0$ to $7.0, \mathrm{Gr}=1.3 \times 10^{6}$ to $5.0 \times 10^{8}, \mathrm{Ar}=0.65$ to 2.6 , and for purely solutal cases are $\mathrm{SC}=2000$ to $2100, \mathrm{Gr}_{\mathrm{m}}=5.0 \times 10^{5}$ to
$1.2 \times 10^{8}$, Ar $=0.68$ to 1.34 . All fluid properties are evaluated at the average temperature of the hot and cold walr's in the thermal cases. In the solutal cases fluid properties are evaluated at the average concentration of the bulk solution.

\section{Test Apparatus}

A sketch of the experimental system is presented in Fig. 1. The test cell is a rectangular enclosure formed with four insulating plexiglas plates and two copper plates (both thermally and electrically conductive). The width, $L$, is $7.7 \mathrm{~cm}$ or $8.2 \mathrm{~cm}$ and the height is variable so that a range of aspect ratios can be covered. The depth of the enclosure is relatively large $(23.9 \mathrm{~cm}$ or $21.2 \mathrm{~cm})$. The two copper horizontal end walls are $0.7 \mathrm{~cm}$ thick.

For the purely thermal cases, an electrical heating mat is bonded to the back of the bottom copper plate and a circulating water system cools the top copper plate ( $F i g .2(a)$ ), so that a uniform temperature can be imposed on the top surface. The plexiglas surfaces are wrapped with $5 \mathrm{~cm}$ thick fiberglass insulation to ensure an adiabatic boundary condition. There are six thermocouples embedded in each copper plate to measure the uniformity of the temperature over the entire surface. A thermocouple probe with a two-dimensional traversing mechanism is inserted into the test section to measure the temperature distribution inside the enclosure. A Leeds and Northrup millivolt potentiometer is used to measure the thermoelectric emf from the copper-constantan thermocouples.

The test field is a copper-sulphate-acid solution $\left(\mathrm{CuSO}_{4}+\mathrm{H}_{2} \mathrm{SO}_{4}+\mathrm{H}_{2} \mathrm{O}\right.$ ) for the purely solutal cases. When a voltage is applied to the electrodes, copper dissoives into the solution at the anode and is deposited at the cathode ( $F$ ig. $2(\mathrm{~b})$ ). As a result, the density of the fluid near the cathode (anode) becomes lower (higher) than that of the bulk of the solution. The migration of cuprlc lons in the electric field is eliminated by adding sulphuric acid to the solution. which acts as a supporting electrolyte, and thus the transport of the cupric ions is controlled only by diffusion and convection. The equipment for measuring the current and potential are shown schematically in Fig. 2. A dc power supply was used in the tests as the power source to the test cell and two digital multimeters are necessary to obtain values of current corresponding to each potential setting. A potential recorder was used to record the voltage as a function of time.

\section{Test Procedure}

The method used to visualize the flow patterns in the present work for purely thermal cases is an electrochemical method called the ph-indicator method. 4 For this test thymol blue is added to the water in the contalner to produce 0.01 percent by weight solution, and then the ph of the solution is adjusted to place it on the yellow side of the end-point. Two electrodes are placed in the solution. When a dc voltage (about $6 \mathrm{~V}$ in the present experiment) is applied between the electrodes, a small volume of colored solution forms around one of the electrodes and moves from the electrode with the fluid motion forming a neutrally buoyant marker. The color change occurs 
because the color of the basic form of thymol blue (blue) is different from that of the acid form (yellow).

Although the temperature of the copper walls can be easily measured by thermocouples, the concentration levels at the walls can not be so easily determined. One relatively simple way to set the concentration level at the cathode in the present system is to adjust the cell potential in such a way that the saturation (limiting) current is obtained. Under the limiting current condition the ion concentration at the cathode surface is zero. In other words, the change in concentration across the solutal boundary layer along the cathode $(\Delta C)_{\text {cathode }}$ ) is $C_{b}$. The limiting-current condition is valid at the cathode but not along the anode surface. However, since the net mass fluxes at the cathode and anode are consldered to be equal and since the concentration outside the solutal boundary layers of both walls is $C_{b}$. it is reasonable to expect that the average change in concentration across the solutal boundary layer along the anode $\left.(\Delta C)_{\text {anode }}\right)$ is nearly equal to $(\Delta C)$ cathode. Then, the overall concentration difference across the cell is $\Delta C=(\Delta C)$ cathode + $(\Delta C)_{\text {anode }}=2 C_{b}$ and thus $G_{m}$ is defined based on $\Delta C=2 C_{b}$ in the present work. The above concept assumes that $C_{b}$ remains constant, but as convection develops in the cell the concentration level remains constant only on the average. Moreover, due to electrolys is the copper wall surfaces become rough slowly with time, which causes the current densities at the walls to decrease and the cathode deviates gradually from the $1 \mathrm{imlting-}$ current condition. For this reason, the duration of each run for the pure solutal cases is $11 \mathrm{mited}$ to $2 \mathrm{hr}$, far shorter than the time required to attain steady solutal convection. It should thus be evident that the concentration boundary conditions are not as well-defined as the thermal conditions. After each run the electrodes are carefully cleaned and polished.

The cell voltage is increased stepwise by a manual control and the corresponding total current is read after each steady state is attained. This procedure is repeated until a potential-current plateau is obtalned. The potential stepping rate is chosen as $20 \mathrm{mV} / 40 \mathrm{sec}$. The flow pattern and the concentration distributions are visually observed. Since the density of the solution changes with cupric ion concentration a qualitative picture of the flow configuration is obtained from the shadowgraph techniques.

\section{Experimental Results}

\section{Purely Thermal Cases}

The flow structures were studied by the aforementioned ph-indicator technique. Based on these observations the flow structures are shown in Figs. 3 to 5 . "Thermals" rising from the bottom of the test cell and falling from the top of the test cell are evident. The dominant motion in the test cell is that of the thermals. 5,6

Figure $6(a)$ and (b) shows typical mean temperature proflies. The mean temperature distributions are presented in the dimensionless form. The magnitude of the temperature, $\bar{T} z-T C$, is normalized by the temperature difference, $\Delta T$, across the layer. The subscript $z$ denotes a condition at a distance $z$ from the bottom plate. It was found that the temperature changed sharply near the top and bottom plates'and the temperature distribution of the bulk flow was uniform. To record temperature disturbances induced by the thermals, the thermocouple probe was placed as near as possible to the bottom and top surfaces of the test cell. Time series records of the thermocouple output are shown in Figs. 7 and 8 . According to Figs. 7 and 8 the amplitudes of the temperature oscillations increase near the top and bottom plates.

The Nusselt number data for water $(P r=5.5$ to 7.0) for various values of Ar are presented in Fig. 9. The predictions of $\mathrm{Nu}$ by others 5,6 are also shown in this figure for comparison. Nu was found to be proportional to $\mathrm{Ra}_{\mathrm{a}} \mathrm{O} .322$ as seen in Fig. 9. The value of the exponent $(n=0.322)$ points to a heat-transfer mechanism by turbulent eddies. However, there appears to be a small but noticeable difference between the present data $(\mathrm{Hr} \equiv \mathrm{L} / \mathrm{W}=3.22)$ and others' data $(\mathrm{Hr}=1)$. Nu seems to increase slightly with decreasing $\mathrm{Hr}$ (L/W). This dependence of $\mathrm{Nu}$ upon $\mathrm{Hr}$ may be explained if one considers the probably weak horizontal flow motion which can be detected in

Figs. 3 and 4 .

\section{Purely Solutal Cases}

In the present electrochemical system operated under isothermal conditions the deposition of cupric ions on the cathode wall leaves behind less dense fluid. The lighter fluid rises toward the top of the test section. The downward flow in the boundary layer near the anode feeds heavier fluid toward the bottom wall.7 Simple shadowgraph studles (Figs. 10 and 11) suggested a very complex flow structure over the $\mathrm{Sc} G r_{\mathrm{m}}$ range $1 \times 10^{9}$ to $2.4 \times 10^{11}$.

It may be useful to compare in detail the purely solutal convection flow structure with that for purely thermal convection because the overall flow structures look somewhat similar for both cases. An important fundamental contrast, however, in the flow structures produced by purely solutal convection and purely thermal convection is illustrated in Figs. 11 and 5 . In the heat transfer situation there are far fewer convection columns (thermals) than for mass transfer.

The most convenient method for studying rates of mass-transfer by the free convection mechanism is by measuring the maximum rate of the electrode reaction (i.e., limiting current) which may be maintained in the quasi-steady state. With the limiting current per unit area of the cathodes, $i_{1}$, known the mass transfer according to Ref. 7 can be calculated as

$$
h=\frac{i}{z^{\star}} C_{b}
$$

The dimensionless mass transfer rate, the Sherwood number, is defined as

$$
S h=h \frac{d}{D}
$$

In the present electrochemical system the diffusion coefficient is very small so a long time is required to obtain truly solutal convection. Thus, the mass transfer rate measured herein in not a 
steady-state value. However, the solutal boundary layers should be established on a time scale of $\delta_{s} / 0$, which is on the order of $10 \mathrm{sec}$ and is small compared to the time at which the limiting current is measured. The measured mass-transfer rate is not expected to differ much from the steady-state value. This accuracy is probably acceptable particularly in view of the uncertainty in the concentration boundary conditions. The experimental error in $\mathrm{Sh}$ is estimated to be $=10$ percent. A correlation for $S h$, as a function of solutal Rayleigh number ( $\mathrm{SC} G \mathrm{Gr}_{\mathrm{m}}$ ), is presented in $\mathrm{Fig} .12$.

\section{Summary of Results}

The results of the present experiments indtcate that for the range of aspect ratios and Grashof (or Rayleigh) numbers covered:

1. The results for the purely thermal cases are adequately correlated by the equation

$$
\mathrm{Nu}=0.862 \mathrm{Ra}^{0} 0.322
$$

in the range $9 \times 10^{6}<\mathrm{Ra}<2 \times 10^{9}$.

2. Temperature oscillations and the exponent 0.322 found in the purely thermal cases reflect a high degree of flow instability in the present work.

3. For the purely solutal cases the mass transfer data can be correlated by the equation

$$
S h=0.1326\left(S C G r_{m}\right) 0.328
$$

in the range $1 \times 10^{9}<\operatorname{Ram}_{m}<2.4 \times 10^{11}$.

In the present work, comparison of the new correlations of mass-transfer data to the results of heat-transfer investigations could serve to give us some enlightenment about the mechanism of the transport process under discussion.

The figures 9 and 12 show clearly that all results are well correlated by the equations:

$$
\begin{aligned}
N u & =C_{1} R_{a} n \\
S h & =C_{2} R_{m} n,
\end{aligned}
$$

from a practical point of view $n=1 / 3$ is acceptable as a regression parameter, at least withtn the experimental $\mathrm{Ra}$ (or $\mathrm{Ram}_{\mathrm{m}}$ ) range.

It enables a general understanding of convective flow for all important vertical crystal growth methods.

\section{Acknowledgments}

The preparation of this paper was made possible by the National Research Council Program. NASA Lewis Research Center has provided support for L.W. Wang's research on the related topics. The authors are thankful to the chief of Microgravity Sclence and Technology Branch, Mr. J.A. Salzman. for the opportunity.

\section{References}

1. Ostrach, S., "Fluid Mechanlcs in Crystal Growth -- The 1982 Freeman Scholar Lecture," Journal of Fluids Engineering, Vol. 105, No. 1, Mar. 1983, pp. 5-20.

2. Wang, L.W., Chen, C.T., and Chen, J.J., "Flow Patterns of Convection in Enclosures with Vertical Temperature and Concentration Gradients." Proceedings of the 1987 ASME/JSME Thermal Engineering Joint Conference, Vol. 2, P.J. Marto and 1. Tanasawa, eds., ASME, New York, 1987, pp. 235-240.

3. Baker, D.J., "A Technique for the Precise Measurement of Small Fluid Velocities," Journal of Fluid Mechanics, Vol. 26, Pt. 3, Nov. 1966, pp. 573-575.

4. Kamotan 1, Y., Wang, L.W., and Ostrach, S., "Natural Convection Heat Transfer in a Water Layer with Localized Heating from Below, "Natural Convection in Enclosures - 1983, I. Catton and K.E. Torrance, eds., ASME, New York, 1983, pp. $43-48$.

5. Goldstein, R.J. and Tokuda, S., "Heat Transfer by Thermal Convection at High Rayleigh Numbers." International Journal of Heat and Mass Transfer. Vol. 23, No, 5, May 1980, pp. 738-740.

6. Tanaka, H. and Miyata, H., "Turbulent Natural Convection in a Horizontal Water Layer Heated from Below," International Journal of Heat and Mass Transfer, Vol. 23, No. 9, Sept. 1980, pp. 1273-1281.

7. Wilke. C.R., Eisenberg, M., and Tobias, C.W., "Correlation of Limiting Currents Under Free Convection Conditions." Journal of the Electrochemical Soclety. Vol. 100. No. 11. Nov. 1953, pp. 513-523. 


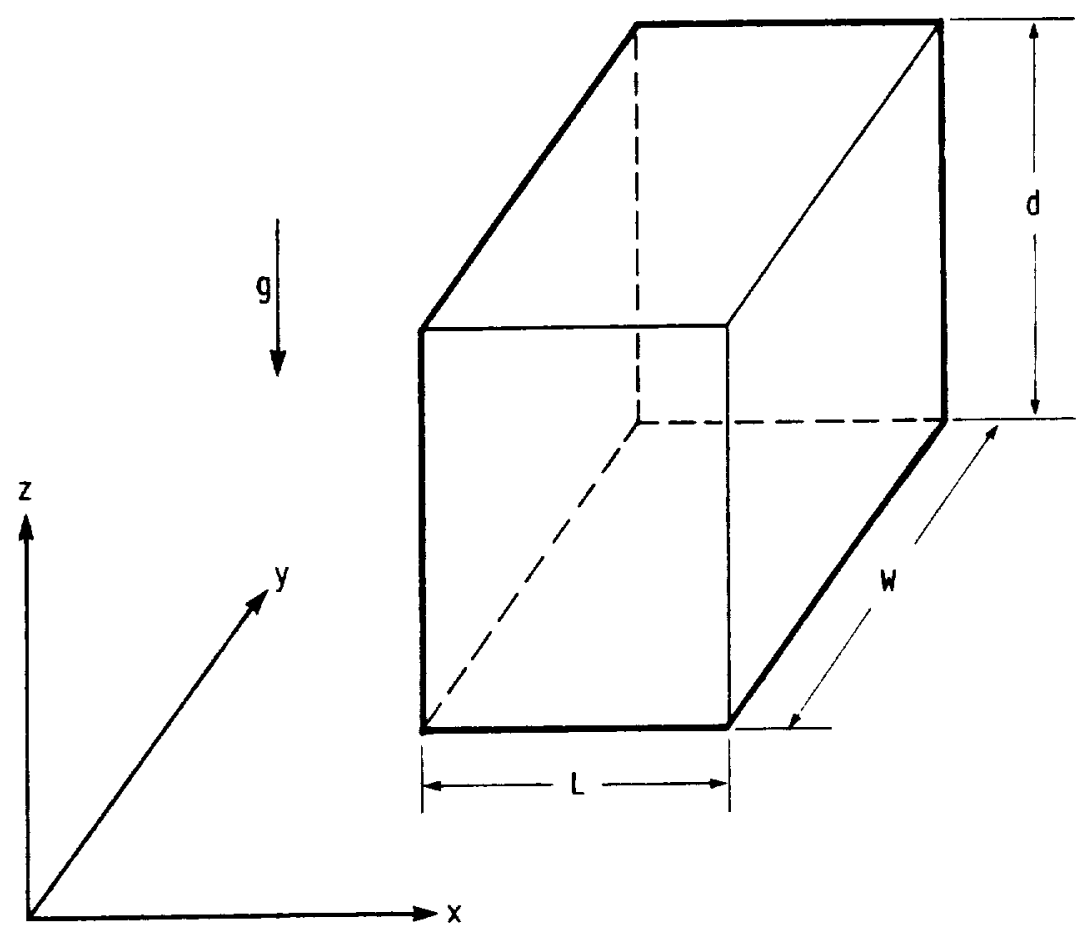

(a) SCHEMATIC.

\begin{tabular}{|c|c|c|c|c|}
\hline $\begin{array}{l}\text { EXPERIMENTAL } \\
\text { SYSTEM }\end{array}$ & L. & $\begin{array}{l}\text { W. } \\
\text { MM }\end{array}$ & MM & Ar \\
\hline \multirow{3}{*}{ MASS TRANSFER } & \multirow{3}{*}{82} & \multirow{3}{*}{212} & 56 & 0.68 \\
\hline & & & 84 & 1.02 \\
\hline & & & 110 & 1.34 \\
\hline \multirow{3}{*}{ HEAT TRANSFER } & \multirow{3}{*}{77} & \multirow{3}{*}{239} & 50 & 0.65 \\
\hline & & & 100 & 1.30 \\
\hline & & & 200 & 2.60 \\
\hline
\end{tabular}

(b) DIMENSIONS.

FIGURE 1. - TEST CELL. 


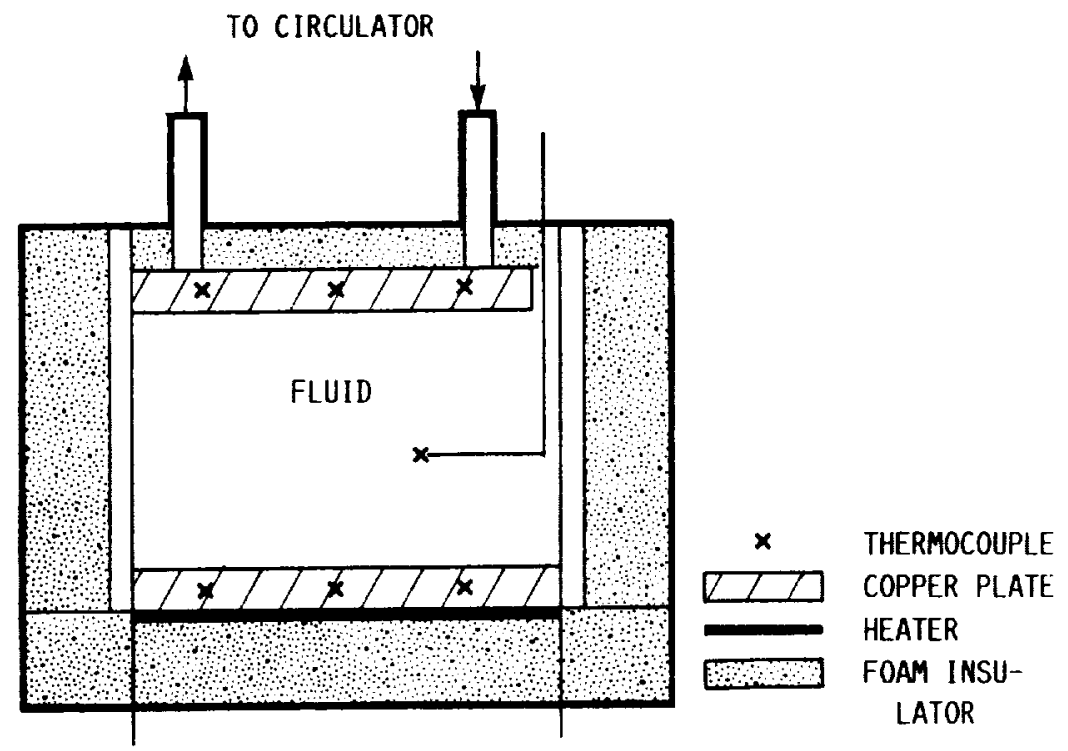

(a) HEAT TRANSFER.

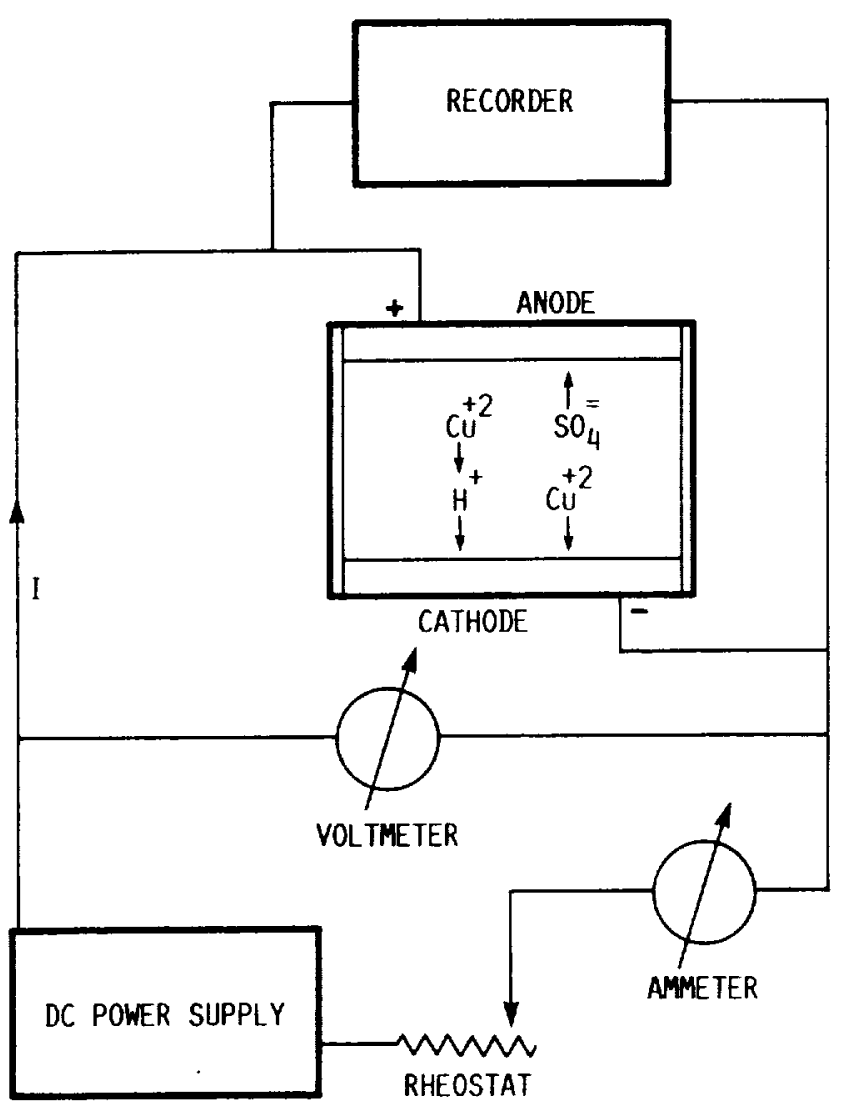

(b) MASS TRANSFER.

FIGURE 2. - EXPERIMENTAL SYSTEMS. 


\section{ORIGINAL PAGE IS \\ OF POOR QUALITY}

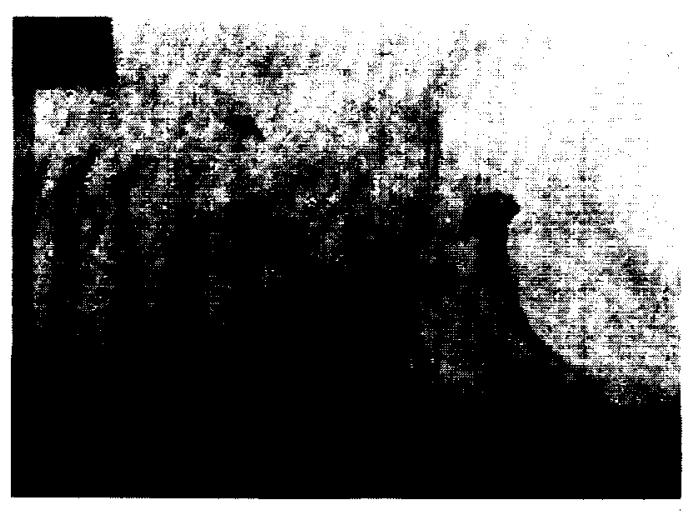

(a) $t_{1}$.

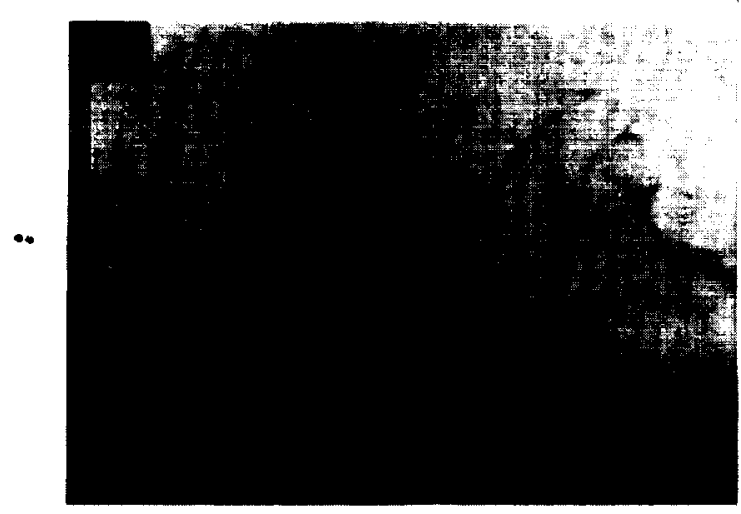

(c) $t_{3}$.

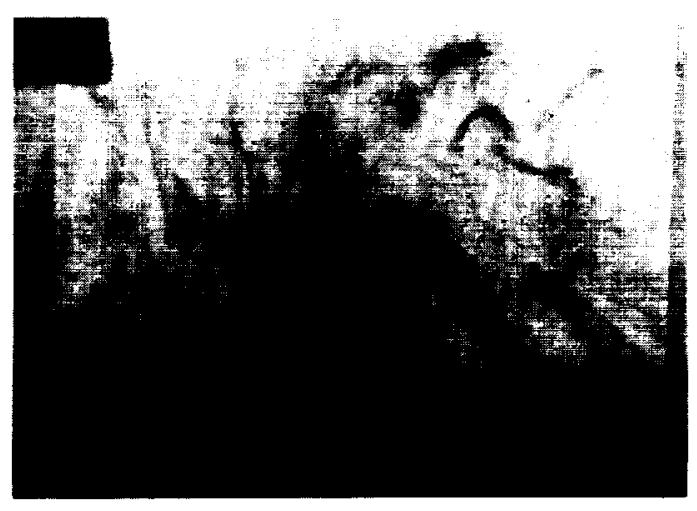

(b) $t_{2}$.

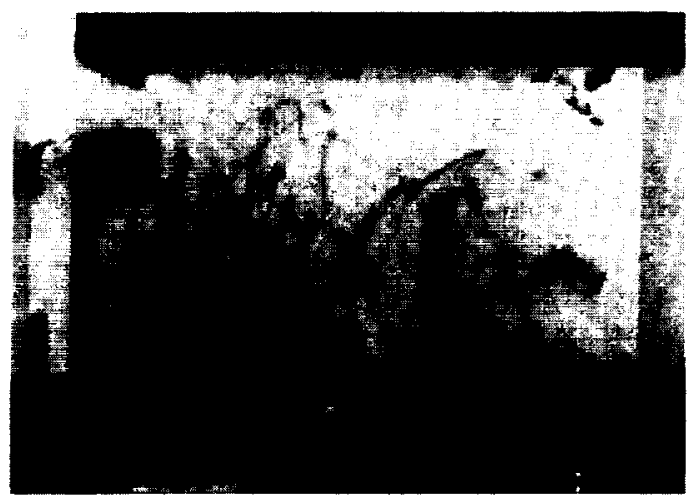

(d) $t_{4}$.

FIGURE 3. - FLOW PATTERNS NEAR THE HEATED LOWER PLATE (PURELY THERMAL CASE) WITH $\mathrm{Ar}=0.65 ; \mathrm{Ra}=1.51 \times 10^{7} ; t_{1}<t_{2}<t_{3}<t_{4} \cdot \Delta t=5 \mathrm{SEC} ; \bar{y}=0$ To 0.5 . 
ORIGNAL PAGE IT

OF. POOR QUALITY

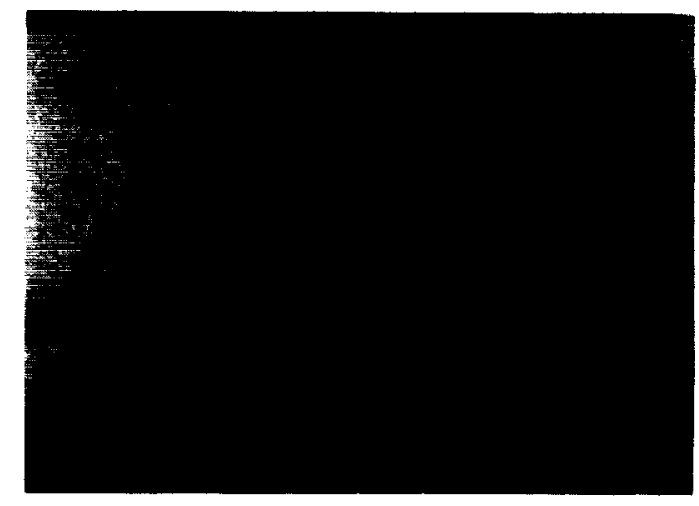

(a) $t_{1}$.

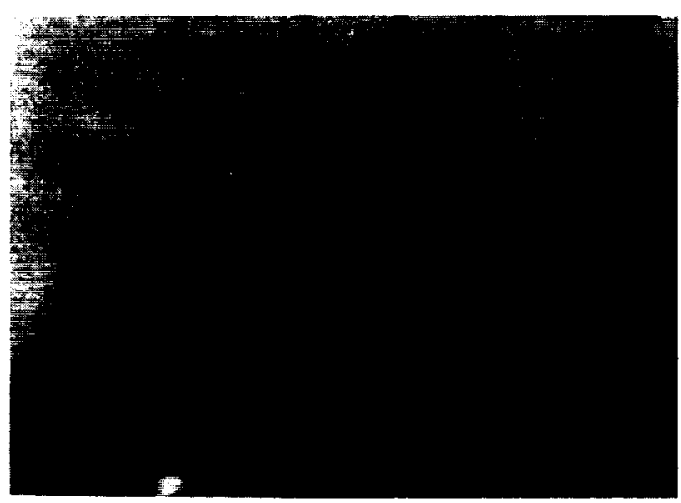

(c) $t_{3}$.

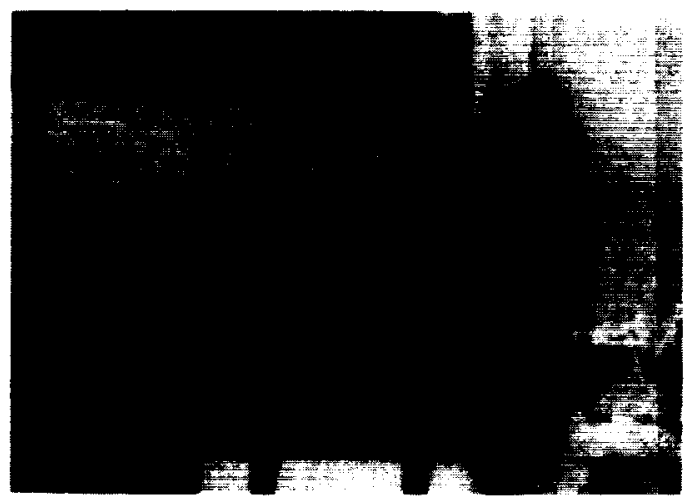

(b) $t_{2}$.

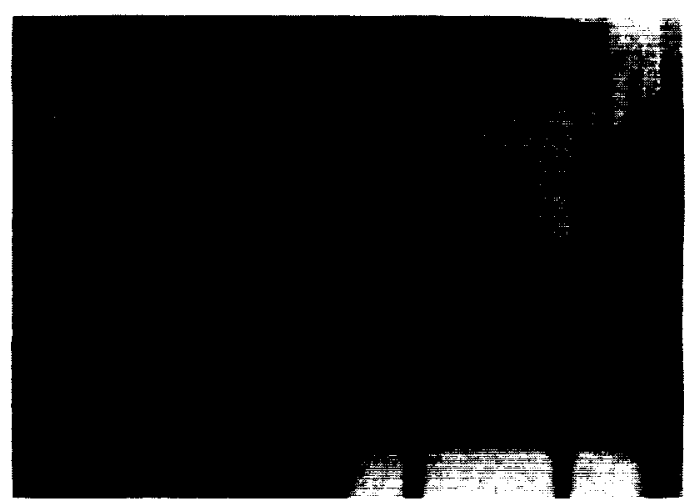

(d) $t_{4}$.

FIGURE 4. - FLOW PATTERNS MEAR THE LOWER PLATE (PURELY THERMAL CASE) WITH AT $=0.65$ : $\mathrm{Ra}=1.51 \times 10^{7}: t_{1}<t_{2}<t_{3}<t_{4}: \Delta t=5 \mathrm{sEC} ; \bar{y}=0.6$ TO 1.0 . 
ORIGINAL PAGE IT

OF POOR OUALIT'

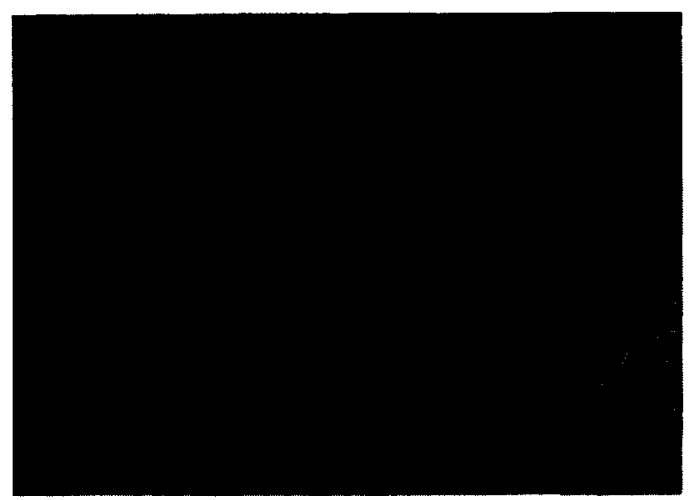

(a) $t_{9}$.

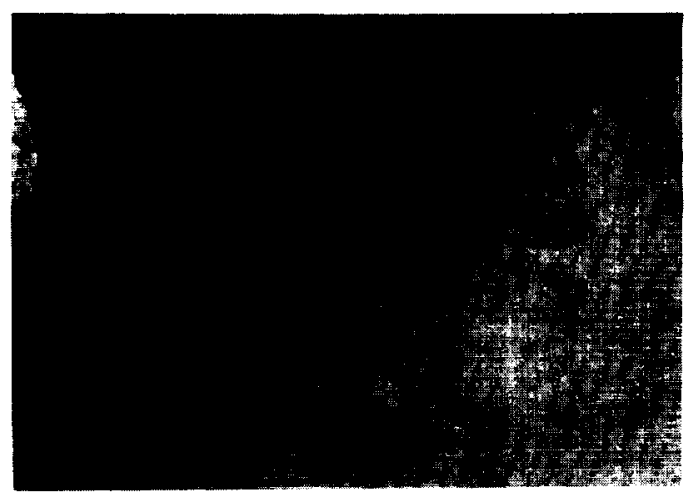

(b) $t_{2}=t_{1}+5 \mathrm{sEC}$.

FIGURE 5. - FLOW PATTERNS MEAR THE COLD TOP PLATE (PURELY THERMAL CASE) WITH $A r=1.30: R a=1.35 \times 10^{8}: t_{1}<t_{2}:$ $\Delta t=5$ SEC. 


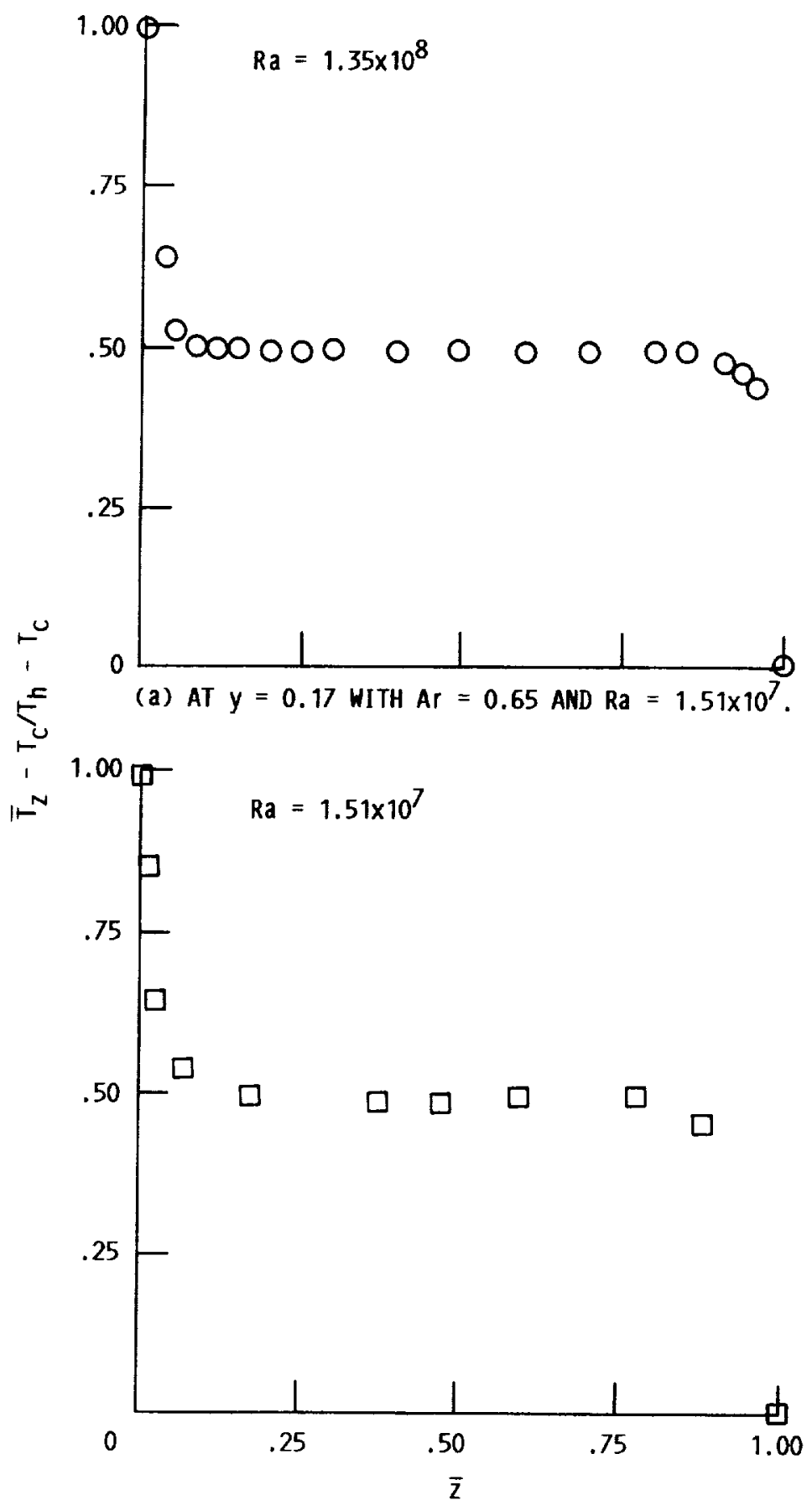

(b) AT $y=0.37$ WITH Ar $=1.30$ AND Ra $=1.35 \times 10^{8}$. FIGURE 6. - TEMPERATURE PROFILES AT $x=0.52$ FOR PURELY THERMAL CASE. 

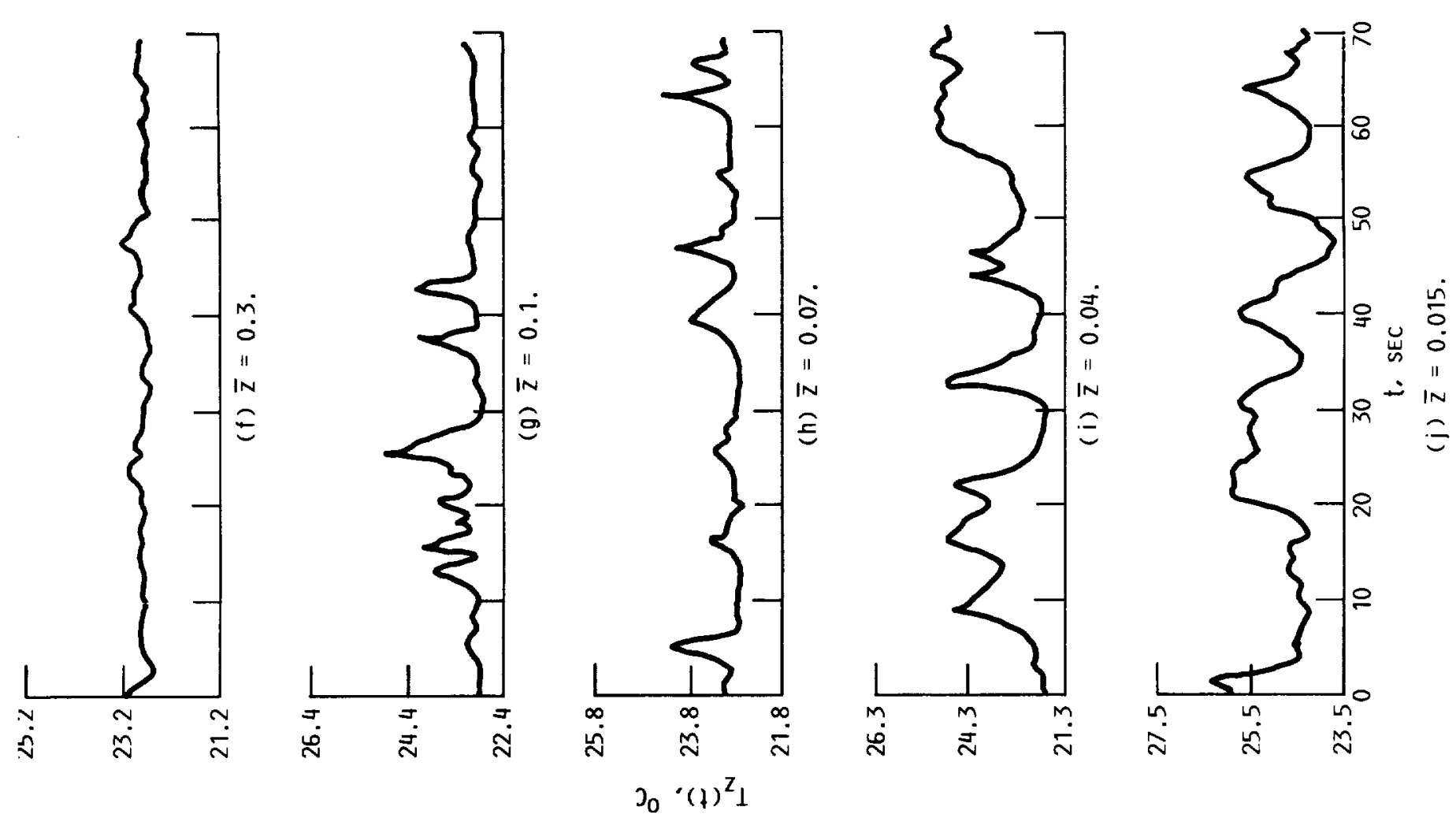

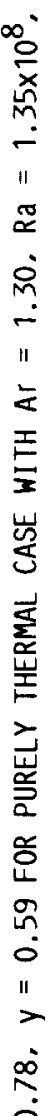
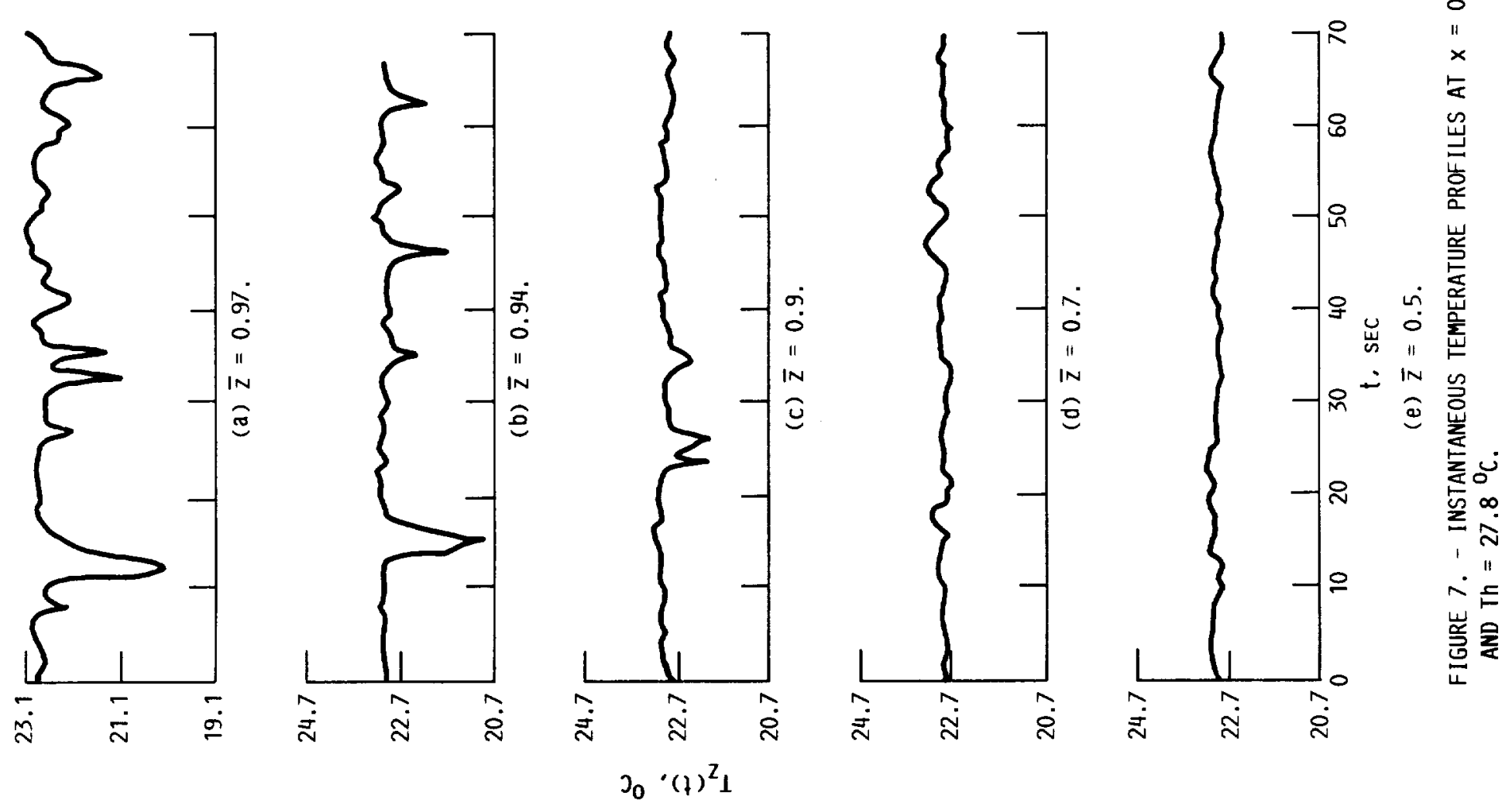

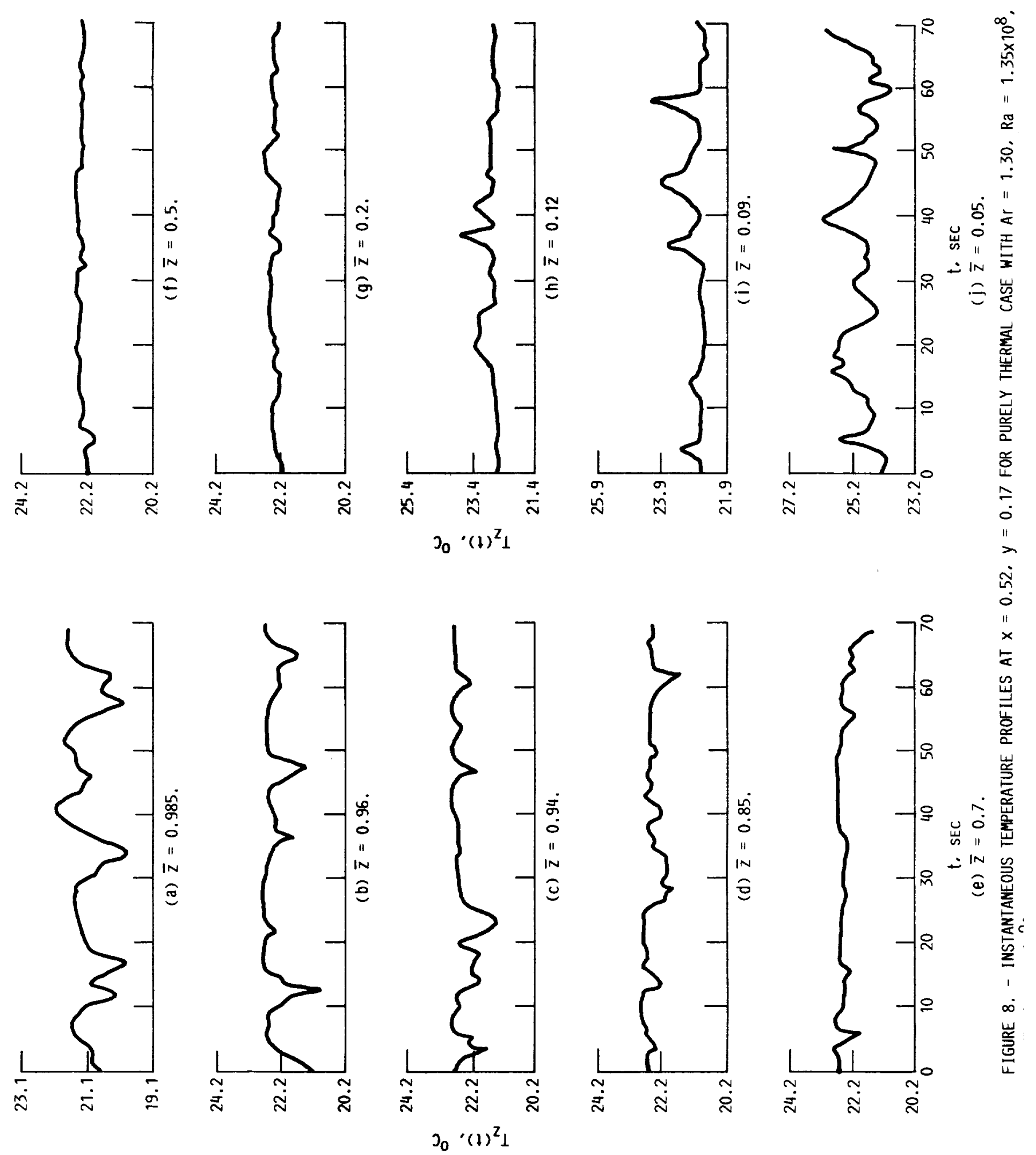


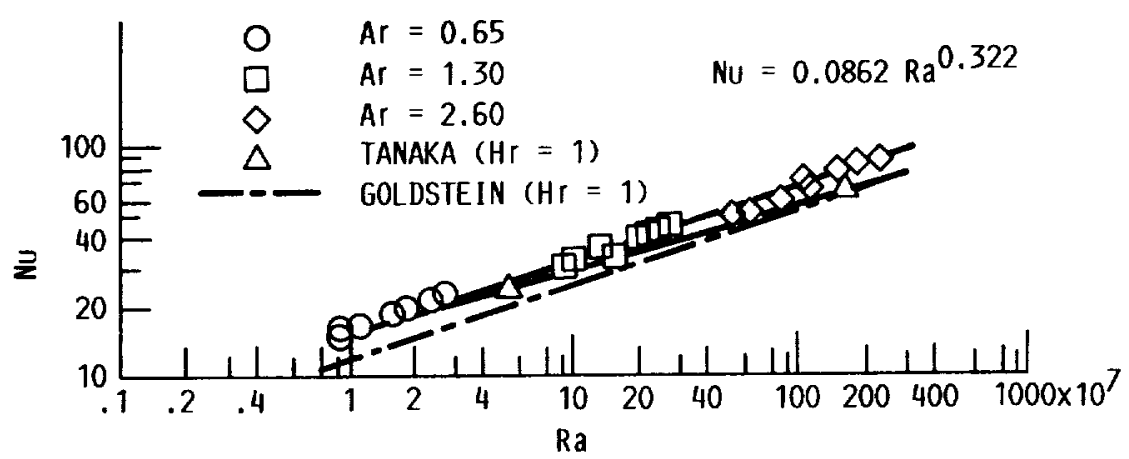

FIGURE 9. - CORRELATION OF NU FOR PURELY THERMAL CASE. $\mathrm{Hr}=0.322$ (PRESENT CASE).

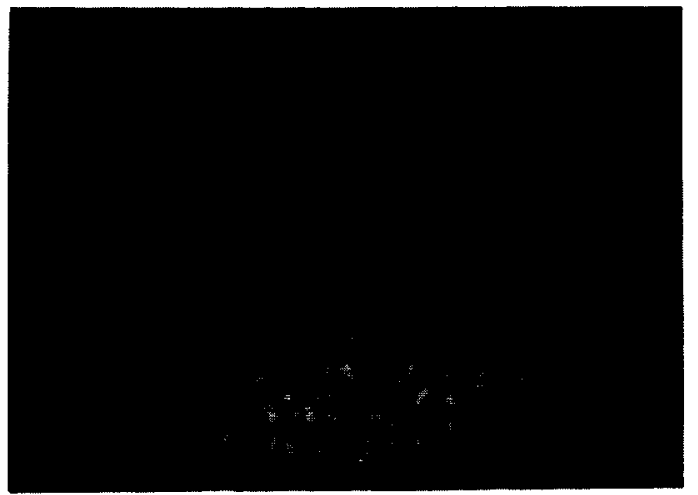

(a) $t_{1}$.

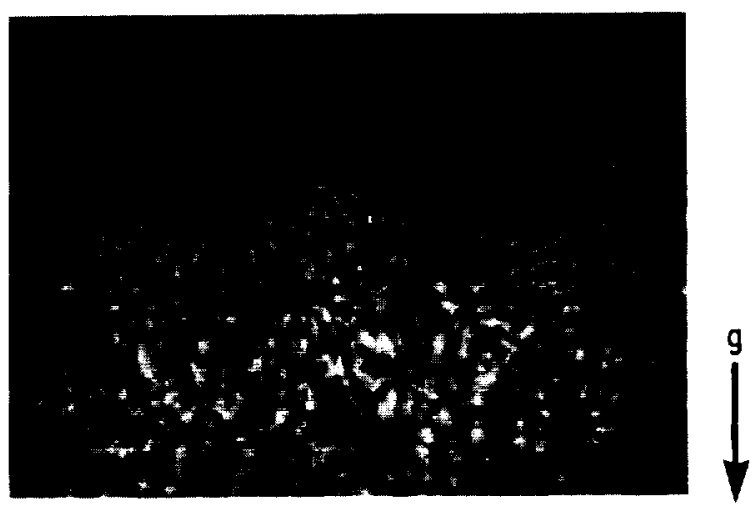

(b) $t_{2}=t_{1}+5$ sEC.

FIGURE 10. - FLOW PATTERNS NEAR THE CATHODE LOWER PLATE (PURELY SOLUTAL CASE), $A r=1.02, R a m_{m}=2.08 \times 10^{11}, t_{1}<t_{2}$. $\Delta t=5$ SEC. 


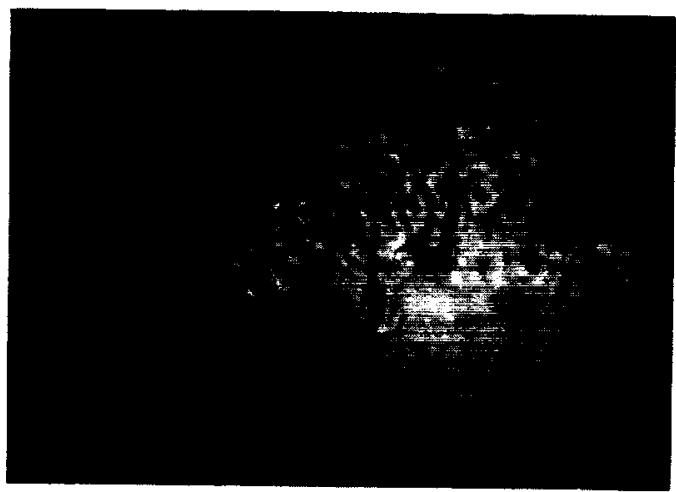

(a) $t_{1}$.

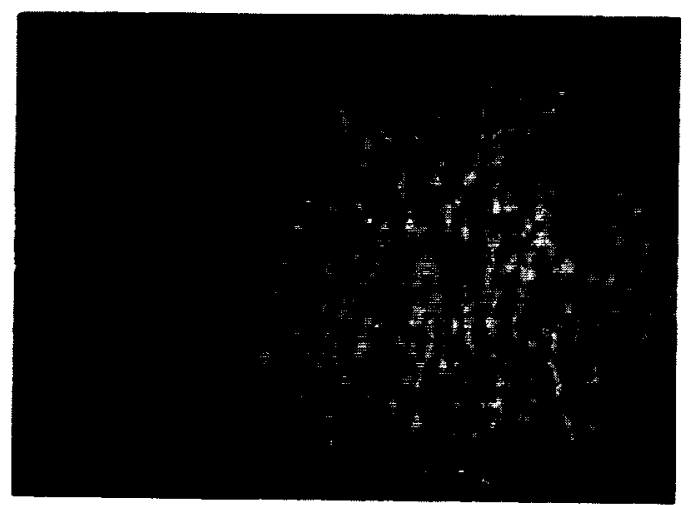

(b) $t_{2}=t_{1}+15 \mathrm{SEC}$.

FIGURE 11. - FLOW PATTERNS MEAR THE ANODE TOP PLATE (PURELY SOLUTAL CASE).

$A r=1.02, R_{m}=2.08 \times 10^{11}, t_{1}<t_{2}$. $\Delta t=15$ SEC.

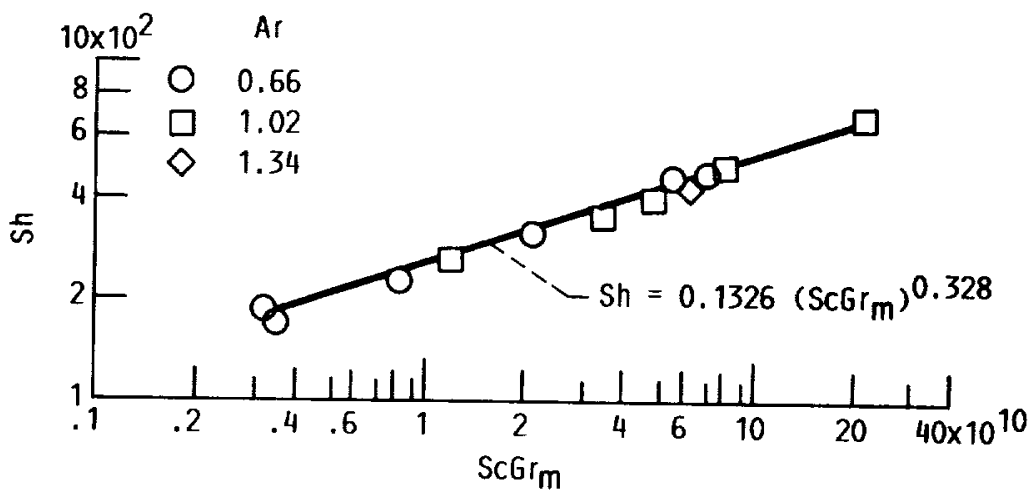

FIGURE 12. - CORRELATION OF Sh FOR PURELY SOLUTAL CASE. 


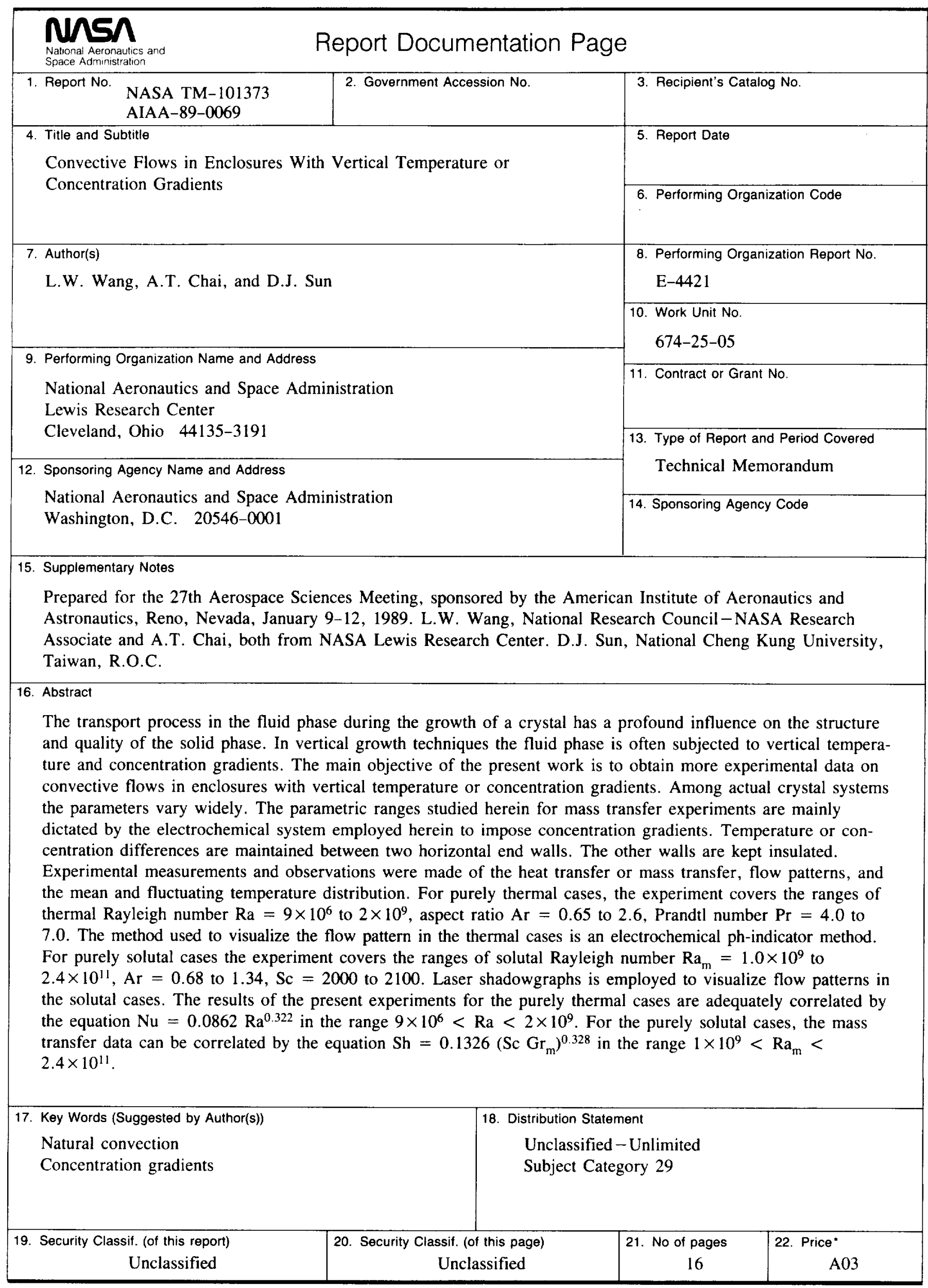




National Aeronautics and Space Administration

Lewis Research Center

Cleveland, Ohio 44135

Otficisl Business

Penalty for Private Use $\mathbf{5 3 0 0}$

\section{ADDRESS CORRECTION REQUESTED}

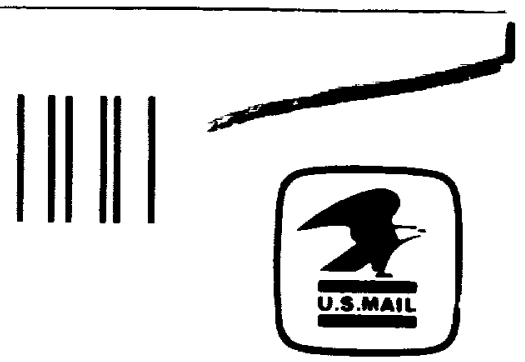

Fimage and Feed Pidi

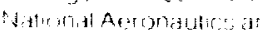

Siberre Adrribistratm

NASA 45 : 